\title{
A VESPA DO PARNASO, DE FAUSTINO XAVIER DE NOVAIS: UMA CARTA DE INTENÇÃO
}

Eliana Petrillo Januzzi

Mestre em Letras: Literatura Brasileira - UFMG

\begin{abstract}
RESUMO
Estudo desenvolvido a partir da página de rosto de A vespa do Parnaso, o qual permite inferir que essa obra - a primeira publicada por Xavier de Novais - representou, na verdade, uma tomada de posição quanto ao gênero satírico que o poeta adotaria dali por diante.
\end{abstract}

\section{PALAVRAS-CHAVE}

Literatura portuguesa, sátira, Xavier de Novais

A vespa do Parnaso, obra satírica de Faustino Xavier de Novais, causou escândalo quando de sua publicação, em 1854, na então pequena e provinciana cidade do Porto. Novais era ligado à boêmia literária daquela cidade, amigo de Camilo Castelo Branco, que saudou, com entusiasmo, esse primeiro volume de versos de Novais: "uma galeria de retratos tirados de perfil, a furto e de passagem, à maneira que os originais te acotovelavam nas praças, nos botequins e nos salões.” ${ }^{1}$

A vespa do Parnaso é constituída por dez poemas, todos compostos na linha da tradição moral, própria do gênero satírico. O conjunto dos poemas apresenta uma unidade, dando a perceber uma organização estabelecida previamente. O primeiro deles, “A Vespa”, poema-chave da obra, é autorreferente. Ali, a persona satírica anuncia o seu propósito, como que resumindo, em décimas, tipos que viriam a ser satirizados nos poemas seguintes. Uma recolha desses tipos é feita na última décima, endereçada ao leitor - o mesmo leitor destinatário do último soneto do livro -, numa espécie de fechamento do plano inicialmente apresentado.

\footnotetext{
${ }^{1}$ Branco citado por MASSA. A juventude de Machado de Assis, p. 345.
} 
Estudos desenvolvidos a partir da página de rosto de A vespa do Parnaso demonstram que esta apresenta um ponto de ancoragem em certo trecho do primeiro poema aí publicado. Abaixo uma reprodução da página de rosto citada, o que facilitará a compreensão do raciocínio aqui proposto:

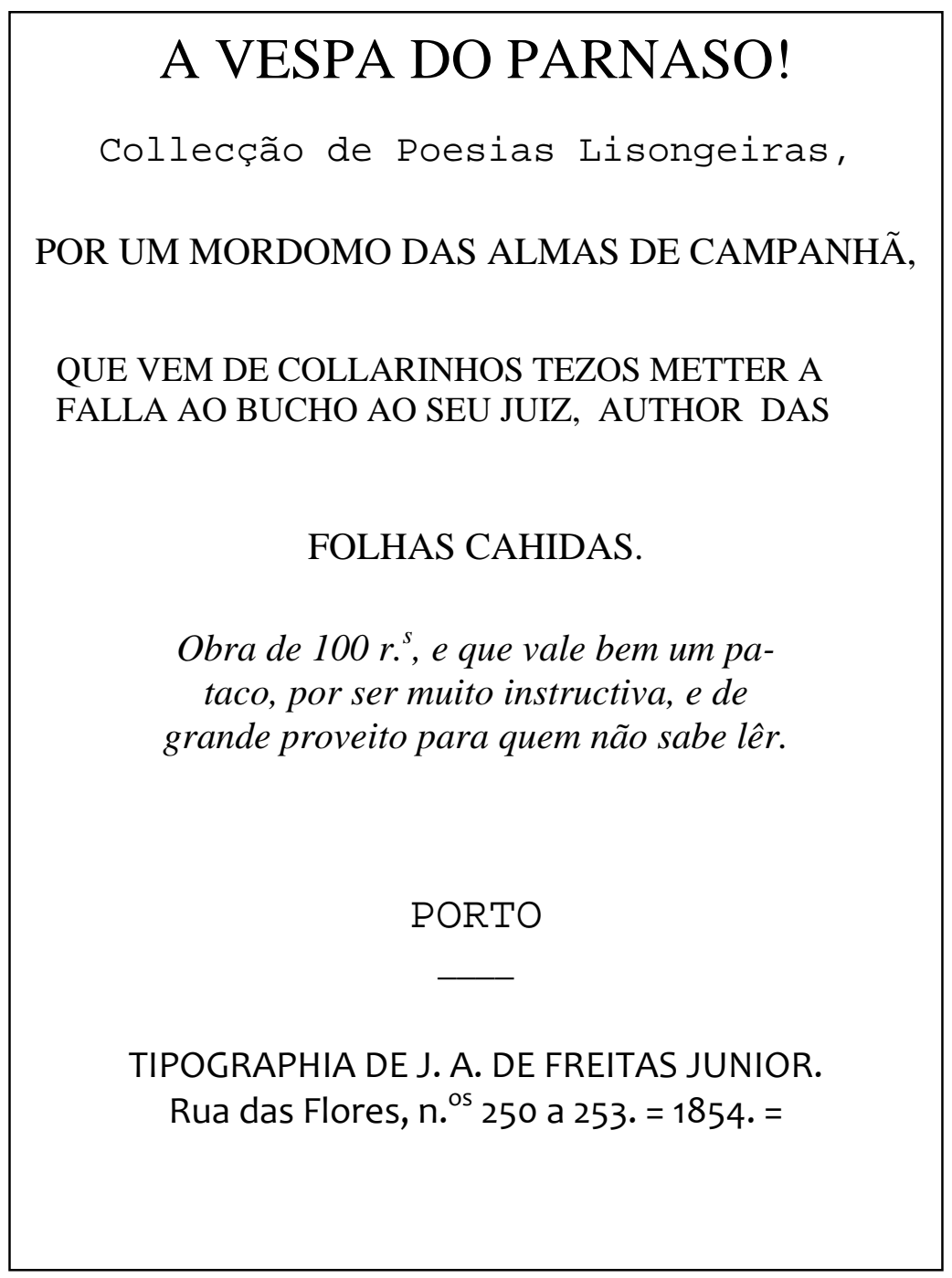

A referência a Folhas caídas não aparece apenas na capa da obra, mas também no verso 56 - abaixo transcrito - do poema intitulado “A Vespa”, no qual esse inseto é a personificação do poeta, que ameaça punir, picando, todos aqueles que não se enquadram no seu conceito de virtude, dentre esses a dama que quer ser literata - a quem, especificamente, o poema condena por sua presunção, com a sugestão de que "Não se meta em danças altas / Entretenha-se a fiar.” (v. 49-50) Ao final da estrofe, tem-se o seguinte aconselhamento, agora no plural:

55 Tolas! nas horas perdidas,

56 Pegai nas Folhas caídas, 
Sanches de Frias, autor de estudo biográfico-literário sobre Xavier de Novais, dá notícia de que, com a publicação de $A$ vespa do Parnaso e em consequência da referência à expressão Folhas caídas contida na indicação de autoria, acreditou-se, num primeiro momento, que Novais se referia a Almeida Garrett, único autor de obra com esse nome - no que Sanches de Frias não acredita. Para ele, o texto impresso na capa faz referência a Camilo Castelo Branco, que, pouco depois do aparecimento de Folhas caídas, de Garrett, e meses antes da publicação de $A$ vespa do Parnaso, fizera publicar um livro de versos intitulado Folhas caídas, apanhadas na lama, sob o pseudônimo de "Um antigo juiz das almas de Campanhã e sócio atual da Assembleia Portuense, com exercício no Palheiro”.

Além da especulação de que a referência feita por Novais a Folhas caídas dissesse respeito à obra de Garrett, também foi dito e escrito, na época, que A vespa do Parnaso poderia ser uma resposta a Camilo Castelo Branco. Para Sanches de Frias não se trata de uma resposta, mas, simplesmente, de uma referência à obra de Camilo, “a quem Novais somente aludiu no frontispício do seu escrito, como se acaba de ver, chamando-se, modestamente, mordomo do Juiz de Campanhã”, 2 já que, ainda segundo ele, os assuntos de um não se prendem aos assuntos do outro.

Uma nova possibilidade de entendimento da menção feita por Novais a Folhas caídas pode ser pensada a partir da vinculação entre a página de rosto e o verso 56 do poema “A Vespa”, acima mencionado, "Pegai nas Folhas caídas”, e, ainda, levando-se em conta as trajetórias de Novais e Camilo, marcadas por afinidades literárias e de cunho social. Vale lembrar que aquele era um momento em que a sátira desempenhava na sociedade um papel específico, no qual Xavier de Novais estava incluído, como atesta Luís de Sousa Rebelo:

Logo que se torna visível a feição burguesa da nova estrutura social, o desencanto e a revolta individualista formulam o primeiro protesto na poesia de Faustino Xavier de Novais contra os brasileiros e barões, a sua cupidez argentária e o seu reacionarismo. ${ }^{3}$

Com relação à suposição de que Novais se referia à Folhas caídas de Garrett, não nos parece convincente que um poeta satírico comprometido com a denúncia social desse destaque na capa do seu livro a uma obra que, como registra Naief Sáfady, contém uma

\footnotetext{
${ }^{2}$ FRIAS. Introdução e notas, p. 182.

${ }^{3}$ REBELO. Sátira, p. 737-747.
} 
“poesia lírica no sentido mais próprio da expressão, pois todas as objetividades esbatem-se em função do sujeito, numa tentativa de 'redescoberta' do mundo dentro de si”. 4

Também nos parece simplista a ideia de que Novais tenha se autointitulado “mordomo” apenas por modéstia, como sugere Sanches de Frias. Analisando a significação e os usos desse vocábulo, percebe-se que essa nem seria uma atitude tão modesta assim. Mordomo, do latim vulgar majordomu, é dicionarizado, hoje, como "administrador dos bens de uma casa, de uma irmandade, de uma confraria”. Jucá Filho registra mordomo-mor como “fidalgo encarregado da mordomia principal”. E Dina Rodrigues Macias, em estudo recente sobre o dialeto rionorês, falado em Rio de Onor, uma freguesia portuguesa do Concelho de Bragança, dá notícia de que o mordomo exerce, ainda hoje, função da maior importância na organização daquela sociedade. Trata-se de uma comunidade híbrida, já que formada por uma aldeia dividida em dois pequenos núcleos populacionais: um espanhol e um português, distantes um do outro 150 metros. Embora separados por fronteira política, possuem a mesma cultura, o mesmo dialeto, os mesmos costumes e a mesma economia. Assim, torna-se obrigatória a livre circulação entre esses povos, cuja sociedade é constituída por famílias, chamadas “vizinhos” e que são governadas por um Conselho formado por dois mordomos, num sistema de votação cíclica. Macias dá uma ideia do papel que representam os mordomos nessa organização

Todas as atividades do conselho e dos mordomos, embora sujeitas à tradição, adaptam-se às novas circunstâncias, mas sempre dentro dos princípios estabelecidos pelo costume. (...) Aqueles mordomos são também os responsáveis por todas as despesas públicas correntes, pela cobrança de multas e pela gestão dos bens da comunidade. Quando da preparação da eleição dos novos mordomos, normalmente no dia do Ano Novo, os mordomos cessantes, além de chamarem a atenção dos vizinhos para a necessidade de escolherem bem os novos mordomos, por se tratar de um cargo muito importante, pois vão eleger/escolher aqueles que irão dirigir os interesses da povoação, apresentam ainda as contas relativas ao ano em que eles conduziram aquele povo. ${ }^{5}$

Assim, intitular-se “mordomo das almas de Campanhã” não nos parece pouca coisa. Campanhã é uma freguesia portuguesa do Concelho do Porto, tendo sido vila e sede desse Concelho até 1836. Vale registrar que o seu patrimônio é constituído, dentre outros, pelo Palácio do Freixo, pelo ex-edifício da Secretaria de Estado da Cultura e pela Igreja de Campanhã.

\footnotetext{
${ }^{4}$ SÁFADY. Folhas caídas: a crítica e a poesia, p. 100.

${ }^{5}$ MACIAS. Dialeto rionorês: contributo para o seu estudo, p. 14-15.
} 
Por tudo isso, é de se acreditar que Novais, mais do que apenas “aludir” ao amigo, dispôs-se, a partir da capa do livro, a perfilar com ele na prática da sátira, ou seja, a filiar-se estética e ideologicamente a Camilo Castelo Branco.

Um dos caminhos que nos levam a essa conclusão tem como ponto de partida a menção a "Palheiro”, feita por Camilo, na capa de Folhas caídas, apanhadas na lama: “sócio atual da Assembleia Portuense com exercício no Palheiro.”

Três são as notícias a que tivemos acesso do que pode significar "Palheiro”. A primeira vem do próprio Camilo, em texto satírico que imita o gênero dramático, publicado no mesmo ano de 1854, logo depois da publicação de Folhas caídas, apanhadas na lama. Essa "peça” tem por assunto uma sessão realizada no "salão da Assembleia Portuense, denominado Palheiro", em que comendadores ali presentes, caricaturados como caipiras, fazem críticas e pedem providências contra a publicação de "um folheto, alumiado as Folhas caídas apanhadas na lama, no qual semos postos a redículo, com as mais trôpegas ilusões”aqui, uma nota esclarecedora: “Em vulgar: torpes alusões. (Nota do taquígrafo).”6

A segunda nos é dada por Urbano Loureiro, autor do poema “Questão de Palheiro”, que retrata, de forma satírica, a Questão Coimbrã - polêmica ocorrida em Portugal na segunda metade do século 19, na qual os jovens e revolucionários estudantes de Coimbra, adeptos do novo espírito científico europeu, liderados por Antero de Quental e Teófilo Braga, reagiam contra "o velho sentimentalismo, domesticado e retoricizado, do Ultra-Romantismo"” em Portugal.

Por fim, Eça de Queirós, em 1884, em carta dirigida a Oliveira Martins, comenta:

Filho de Aveiro, educado na Costa Nova, quase peixe de ria, eu não preciso que mandem ao meu encontro caleches e barcaças. Eu sei ir por meu próprio pé ao velho e conhecido palheiro do José Estevão (...) Talvez sexta-feira fique na Granja, a respirar o ar puro da verdade social que ali constantemente circula, emanado dos espíritos de Mariano, Henrique Macedo, e outros reforminhas. ${ }^{8}$

Recolhidas essas informações, o termo parece remeter mais a um sentido abstrato de ajuntamento de intelectuais, a uma espécie de academia de ideias, do que ao próprio local físico onde eles se ajuntam.

\footnotetext{
${ }^{6}$ BRANCO. Palheiro, p. 571-580. (Nota do taquígrafo)

${ }^{7}$ CAL. Questão Coimbrã, p. 662..

${ }^{8}$ QUEIRÓS. Correspondência, p. 63-64.
} 
Certo é que a crítica à fidalguia nascida à margem da tradição, assunto que viria a ser recorrente em Novais, fica evidente no texto "O Palheiro", de Camilo Castelo Branco. Reforça, ainda, a inferência da filiação de Novais ao conjunto de ideias e valores do amigo a recomendação contida no verso 56 já mencionado: “Pegai nas Folhas caídas”, que o contexto permite depreender tratar-se da obra de Camilo. Tal como na capa, aqui também Novais suprime a indicação “apanhadas na lama”. Entretanto, é nessa obra - e não na de Garrett - que pode ser encontrado o espírito de discriminação já percebido em “A Vespa”.

Eis transcrição das estrofes que justificam a aproximação dos textos de Camilo Castelo Branco e de Faustino Xavier de Novais:

\begin{tabular}{ll} 
“Elogio Fúnebre” & \multicolumn{1}{c}{ "A Vespa” } \\
a uma dama, prodígio de fecundidade, que dá à \\
luz três romances, por semana, nos jornais do Porto \\
\\
$\begin{array}{l}\text { Cornucópia da toleima, } \\
\text { Nós fizemos-te algum mal? }\end{array}$ & Pois quando encontro uma dama \\
Tu não sabes, escritora? & Que literata quer ser, \\
Como zombam lá por fora & E por fim bespa me chama, \\
Das letras de Portugal? & Sem disso a causa saber?!... \\
Não lucrara mais a pátria, & Não só então a não poupo, \\
E lucraras tu também, & Mas sinto não ter um choupo, \\
Se fiasses numa roca, & Do meu ferrão em lugar; \\
Com primor, a maçaroca, & Se quer desculpa das faltas, \\
Que desprezas, com desdém? & Não se meta em danças altas, \\
& Entretenha-se a fiar. ${ }^{10}$
\end{tabular}

Contrariando afirmação de Sanches de Frias, comentada anteriormente, de que os assuntos de Novais não se prendem aos assuntos de Camilo, a confrontação entre essas décimas demonstra que os dois textos são, sim, variantes de uma mesma estrutura.

Michael Riffaterre ensina que cada texto apresenta, no seu conjunto, uma única unidade significante, unicidade esta que resulta do fato de que o texto, na sua inteireza, deriva, por expansão, de uma única frase matricial. Levando-se em conta que o processo de expansão é determinado por uma série de modelos latentes, que são os textos preexistentes, pode-se concluir que a textualidade tem por fundamento a intertextualidade.

Para que haja intertextualidade, segundo o modelo proposto por Riffaterre, é necessário que os textos que se comprometem atualizem uma invariante e que essa atualização se imponha ao leitor graças às constantes formais e semânticas que se manifestam a despeito de variações estilísticas entre eles. Neste estudo, as constantes que nos fizeram

\footnotetext{
${ }^{9}$ BRANCO. Obras completas, p. 741.

${ }^{10}$ NOVAIS. A vespa do Parnaso, p. 5.
} 
aproximar os textos de Camilo e de Novais estão sintetizadas na seguinte "frase matricial”: “a mulher, desqualificada que é para o trabalho intelectual, deve contentar-se em operar a roca de fiar.” ${ }^{11}$ - frase essa que dá a perceber a identidade estrutural existente entre os poemas.

Por fim, a forma extensa usada na capa do livro de Novais, que indica não apenas a autoria: "Por um mordomo das almas de Campanhã”, mas, ainda, diz a que vem: “meter a fala ao bucho ao seu Juiz, autor de Folhas caídas”, dá força ao entendimento aqui proposto. Essa forma prolixa não se repetiu nos livros que Novais viria a publicar mais tarde, talvez por não se fazer mais necessário reafirmar a posição aí tomada. Tanto parece ser assim que, em edição posterior do poema “A Vespa”, Novais sentiu-se à vontade para alterar os versos 55 e 56 já citados. Ao invés de recomendar Camilo - posição importante e decisiva no seu primeiro livro de versos -, passou a recomendar o grande satírico português Nicolau Tolentino, a quem, diga-se de passagem, Novais era comparado. Assim, "Tolas! nas horas perdidas, / Pegai nas Folhas caídas”, transformou-se em: "Se inda tendes algum tino, / Ide ler o Tolentino.”

Certo é que o poeta parece ter se mantido fiel ao compromisso assumido em A vespa do Parnaso - afinal, à exceção de alguns poemas de circunstância e de uns poucos versos compostos na juventude, não se tem notícia de obra sua, publicada em vida, que não seja satírica e que não tenha por base a crítica ao sistema de valores de uma sociedade que engrandecia o sujeito não por suas virtudes, mas pelo título que ostentava.

\section{RÉSUMÉ}

Étude developé à partir de la page de titre de l'A vespa do Parnaso, lequel permettre inférer que cet œuvre - la première publiée par Xavier de Novais - a representé, en vrai, une pris de position en rélation au genre satirique que le poète adopterais dorénavant.

\section{MOTS-CLÉS}

Littérature portugaise, satire, Xavier de Novais

\footnotetext{
${ }^{11}$ RIFFATERRE. Sémiotique intertextuelle: l’interprétant, p. 128-132.
} 


\section{REFERÊNCIAS}

BRANCO, Camilo Castelo. Obras completas. Justino Mendes de Almeida (Org.). Porto: Lello \& Irmão, v. X, 1989.

BRANCO, Camilo Castelo. Palheiro. In: Obras completas. Justino Mendes de Almeida (Org.). Porto: Lello \& Irmão, 1990. p. 571-578. v. XII.

CAL, Ernesto Guerra da. Questão Coimbrã. In: COELHO, Jacinto do Prado. (Org.). Dicionário das literaturas portuguesa, brasileira e galega. Porto: Figueirinhas, 1960. p. 662.

COELHO, Jacinto do Prado (Org.). Dicionário de literaturas brasileira e galega. Porto: Figueirinhas, 1960. p. 244-248; 737-747.

FERREIRA, Alberto; MARINHO, Maria José. Bom senso e bom gosto (A questão coimbrã). 2. ed. Portugal: Maiadouro, 1866. (Impresso para a Imprensa Nacional / Casa da Moeda).

FRIAS, João Baptista Gomes, Sanches de. Introdução e notas. In: NOVAIS, Faustino Xavier de (Org.). Ignez d'Horta: comédia semi-trágica em 5 actos Lisboa: Viuva Tavares Cardoso, 1906. p. 135-261.

JUCÁ FILHO, Cândido. Dicionário escolar das dificuldades da língua portuguesa. 4. ed. Rio de Janeiro: FENAME/Ministério da Educação e Cultura, 1970.

MACIAS, Dina Rodrigues. Dialeto rionorês: contributo para o seu estudo. Bragança/Portugal: Instituto Politécnico de Bragança, 2003.

MASSA, Jean-Michel. A juventude de Machado de Assis. Trad. Marco Aurélio de Moura Matos. Rio de Janeiro: Civilização Brasileira, 1971.

NOVAIS, Faustino Xavier de. A vespa do Parnaso. Porto: J. A. de Freitas Júnior, 1854.

NOVAIS, Faustino Xavier de. Poesias. 2. ed. Porto: Tipografia de Sebastião José Pereira, 1856.

NOVAIS, Faustino Xavier de. Novas poesias. 2. ed. Porto: [s.n.], 1858.

NOVAIS, Faustino Xavier de. Ignez d'Horta: comédia semi-trágica em 5 actos. João Baptista Gomes, Sanches de Frias (Org.). Lisboa: Viuva Tavares Cardoso, 1906. 261 p.

QUEIRÓS, Eça de. Correspondência. CASTILHO, Guilherme de (Org.). Lisboa: Imprensa Nacional, 1983. v. 1.

REBELO, Luís de Sousa. Sátira. In: COELHO, Jacinto do Prado. Dicionário das literaturas portuguesa, brasileira e galega. Porto: Figueirinhas, 1960. p. 737-747.

RIFFATERRE, Michael. Sémiotique intertextuelle: l'interprétant. In: Rhétoriques, sémiotiques. Revue d'Esthétique, n. 1-2. Paris: Union Générale d'Éditions, 1979.

SÁFADY, Naief. Folhas caídas: a crítica e a poesia. 2. ed. rev. Rio de Janeiro: Livraria Francisco Alves, 1965. (Coleção “Universitas”). 